\title{
A case of alopecia with rickets
}

S K Rajapakse ${ }^{1}$, N N Dissanayake ${ }^{2}$

Sri Lanka Journal of Child Health, 2004; 33: 58-9

(Key words: alopecia, rickets)

\section{Introduction}

Two distinct hereditary defects, Vitamin D dependent rickets type I (VDDR I) and type II (VDDR II) have been recognized in vitamin D metabolism ${ }^{1}$. VDDR I is due to a deficiency of the renal 25-hydroxyvitamin D (25 (OH)D) -1 alpha-hydroxylase ${ }^{1}$. Muscle weakness and rickets are the prominent clinical findings. Normal physiological doses of 1alphahydroxyvitamin D3 and 1,25-dihydroxyvitamin D3 are sufficient to maintain remission of rickets in this disorder ${ }^{1}$. VDDR II consist of a spectrum of intracellular Vitamin D receptor defects and is characterized by the early onset of severe rickets and associated alopecia ${ }^{1}$. Massive doses of vitamin D analogues and calcium supplements are usually required for treatment ${ }^{1}$. The receptor defects are as follows :

1. Reduced or absent binding of 1, 25dihydroxyvitamin D3 to vitamin D nuclear receptor.

2. Decreased affinity of this receptor for DNA transcription.

3. Defective nuclear translocation.

4. Abnormal gene product, which is produced by the vitamin $\mathrm{D}$ receptor gene.

5. Missense mutation of DNA binding or the steroid 1, 25-dihydroxyvitamin D3 of vitamin D receptor.

${ }^{1}$ Consultant Paediatrician, ${ }^{2}$ Paediatric Registrar, Teaching Hospital, Kandy.

(Received on 20 October 2003)

\section{Case report}

A two year old boy from Kegalle, a product of a consanguineous marriage, was admitted to our unit with difficulty in breathing and fever of three days duration. The mother's main worry was the absence of hair since birth.

He was a full term baby with a birth weight of $3 \mathrm{~kg}$ and was exclusively breast-fed for 4 months. Weaning commenced at the appropriate time. His motor development was delayed. He could sit without support but was unable to walk even with support. There was no family history of a similar illness.

On examination, all his growth parameters were 2 standard deviations below the mean. Alopecia totalis, tachypnoea and all the clinical features of rickets with hypotonia and proximal muscle weakness were observed (Figure 1). The respiratory rate was $65 / \mathrm{min}$ but the air entry was equal with no added sounds. Other systemic examinations were normal. The neurodevelopment age was appropriate despite the motor development delay.

Investigations revealed proximal renal tubular acidosis, hypocalcaemia, and hypophosphataemia with markedly elevated alkaline phosphatase level. His urinary examination revealed proteinuria, aminoaciduria and presence of reducing substances. There was radiological evidence of severe rickets with delay in bone age (6-9 months), normal renal scan and normal skin biopsy. Treatment was given with massive doses of vitamin D analogue but he failed to show any response. 


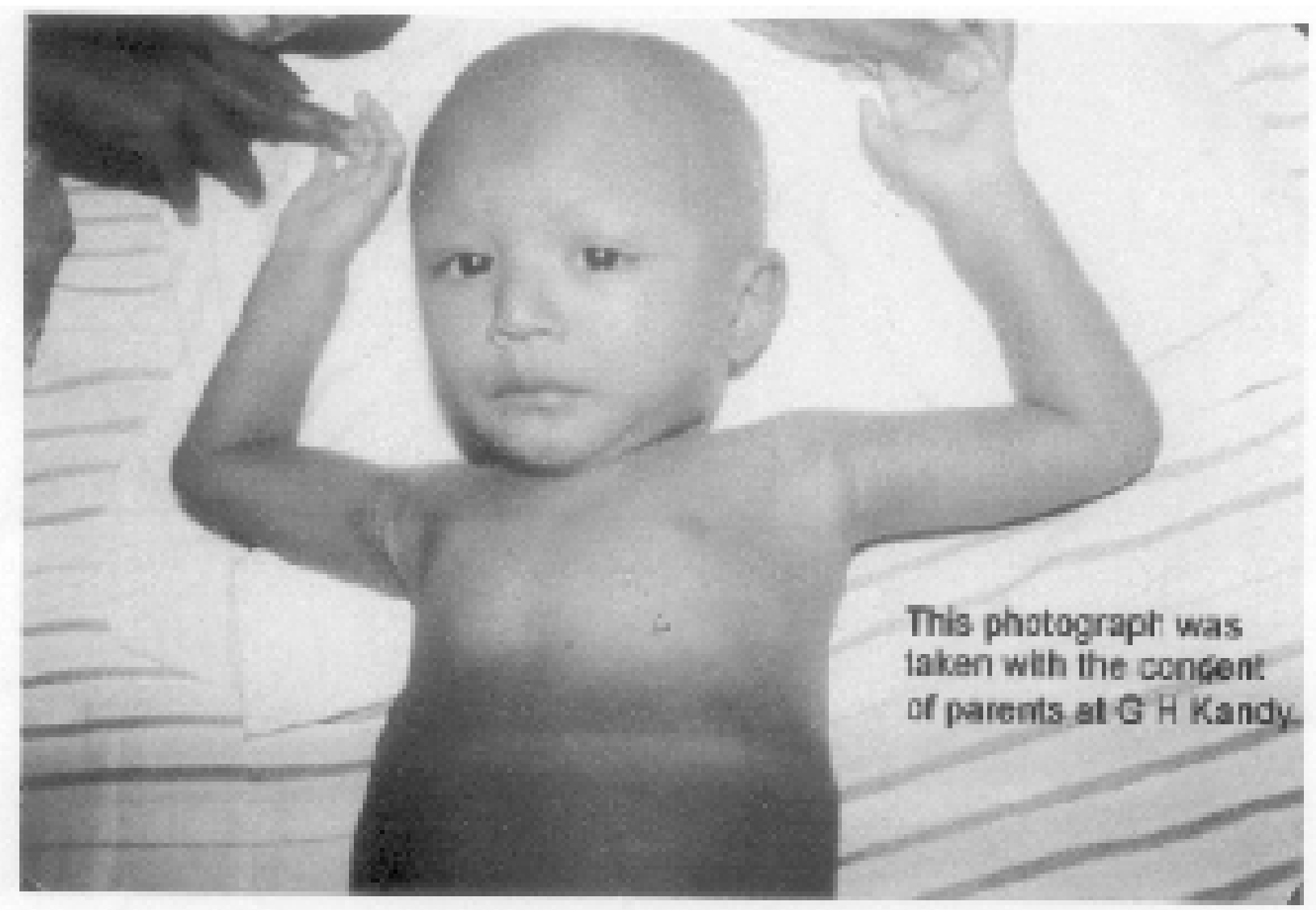

Figure 1

\section{Discussion}

VDDR II is an autosomal recessive condition, mostly prevalent among consanguineous marriages ${ }^{2}$. It is a rare disorder and not previously documented in Sri Lanka. Florid rickets, alopecia, hypocalcaemia and resistance to therapy with high dose of Vitamin D3, characterize the clinical and biochemical picture ${ }^{3}$. In developing countries, due to lack of facilities for estimation of 1,25-dihydroxyvitamin D3, alopecia remains the only clue to the diagnosis of this rare syndrome in association with resistant rickets ${ }^{3}$. In spite of being on massive dose of Vitamin D analogue this child did not show any response even after one year of treatment. Thus a presumptive diagnosis of VDDR II was made.

\section{Acknowledgements}

We thank Kandy Medical Society Unit for their invaluable help.

\section{References}

1. Takeda E, Yamamoto H, Taketani Y, Miyamoto K. Vitamin D-dependent rickets type I and type II. Acta Paediatr Jpn 1997; 39(4): 508-13.

2. Behrman R E editor. Nelson Textbook of Pediatrics. 16th ed. Philadelphia; Saunders 1999; 2137.

3. Gupta P C, Patwari A K, Mullick D N. Alopecia with rickets: an end organ unresponsiveness to 1 , 25 -dihydroxyvitamin D - a case report. Indian $J$ Med Sci 1990; 44(9): 239-43. 